\title{
Synthesis of Polystyrene-Supported Dithizone Analogues for Use as Chemical Sensors for Heavy Metals
}

by

C. W. Jenkins

Westinghouse Savannah River Company

Savannah River Site

Aiken, South Carolina 29808

R. B. King

University of Georgia

GA USA

1. Bresinska

University of Georgia

GA USA

A document prepared for INTERNATIONAL CONFERENCE ON COORDINATION CHEMISTRY at Edinburgh, , Scotland from -.

$$
\text { Camol couf informat incomplit }
$$

DOE Contract No. DE-AC09-96SR18500

This paper was prepared in connection with work done under the above contract number with the U.S. Department of Energy. By acceptance of this paper, the publisher and/or recipient acknowledges the U.S. Government's right to retain a nonexclusive, royalty-free license in and to any copyright covering this paper, along with the right to reproduce and to authorize others to reproduce all or part of the copyrighted paper. 


\section{DISCLAIMER}

This report was prepared as an account of work sponsored by an agency of the United States Government. Neither the United States Government nor any agency thereof, nor any of their employees, makes any warranty, express or implied, or assumes any legal liability or responsibility for the accuracy, completeness, or usefulness of any information, apparatus, product, or process disclosed, or represents that its use would not infringe privately owned rights. Reference herein to any specific commercial product, process, or service by trade name, trademark, manufacturer, or otherwise does not necessarily constitute or imply its endorsement, recommendation, or favoring by the United States Government or any agency thereof. The views and opinions of authors expressed herein do not necessarily state or reflect those of the United States Government or any agency thereof.

This report has been reproduced directly from the best available copy.

Available to DOE and DOE contractors from the Office of Scientific and Technical Information, P.O. Box 62, Oak Ridge, TN 37831; prices available from (615) 576-8401.

Available to the public from the National Technical Information Service, U.S. Department of Commerce; 5285 Port Royal Road, Springfield, VA 22161. 


\section{DISCLAIMER}

Portions of this document may be illegible electronic image products. Images are produced from the best available original document. 


\title{
Synthesis of Polystyrene-Supported Dithizone Analogues for Use as Chemical Sensors for Heavy Metals
}

\author{
R. B. King and I. Bresińska \\ Department of Chemistry, University of Georgia, Athens, Georgia 30602, USA
}

\begin{abstract}
Fiber optic sensors for heavy metal detection require chromogenic ligands which change color upon contact with the metal ions of interest and which can be immobilized onto an insoluble matrix incorporated into the fiber optic system. Diarylthiocarbazone ligands such as dithizone (diphenylthiocarbazone) are of particular interest because of the intense and distinct colors of their complexes with heavy metals of environmental concern such as lead and mercury. This paper describes methods for chemical immobilization of a diarylthiocarbazone unit onto a polystyrene matrix. The key step in the preparation of polystyrene-supported diarylthiocarbazones uses the coupling of nitroformaldehyde $\beta$-naphthylhydrazone with diazotized aminopolystyrene. The resulting polystyrenesupported diarylnitroformazan can then be converted to the corresponding polystyrenesupported diarylthiocarbazone by treatment with aqueous ammonium sulfide followed by oxidation. Using this method samples of polystyrene-supported diarylthiocarbazones have been obtained which undergo distinctive color changes in $0.005 M$ aqueous $\mathrm{Pb}^{2+}$ and $\mathrm{Hg}^{2+}$. The properties of such polystyrene-supported diarylthiocarbazones obtained from diazotized aminopolystyrene and nitroformaldehyde $\beta$-naphthylhydrazone, including their reactions with heavy metal ions, are compared with materials containing an extra azo chromophore obtained by the method of Chwastowska and Kosiarska using the coupling of diazotized aminopolystyrene with di- $\beta$-naphthylthiocarbazone.
\end{abstract}




\section{Introduction}

Fiber optic sensors 1 ,2,3,4,5,6,7 require chromogenic ligands for monitoring heavy metals through color changes occurring in the presence of small quantities of the metals of interest. Of particular interest are ligands suitable for monitoring the toxic lead and mercury cations which are "soft" acids in the Pearson sense thereby having a higher affinity for sulfur ligands than oxygen ligands. Ideal chromogenic ligands for such metals should have the following properties:

(1) The metal-ligand complex must be highly colored even in low metal concentrations and must have a color distinct from that of the uncomplexed reagent. For this reason ligands which have the highly chromophoric azo group are of particular interest.

(2) The metal complexation should be chemically reversible so that optical sensors containing such ligands can monitor varying metal ion concentrations.

(3) The chromogenic indicator should be selective for particular metal ions to reduce chemical interference.

(4) Both the ligand and its metal complexes must be stable in the environment where they are used.

This objective thus requires the development of highly colored chromogenic ligands with selective heavy metal complexing abilities as well as methods for incorporating such ligands into optic sensors through suitably chosen immobilization procedures.

Diverse methods have been used for the immobilization of ligands on the silica surfaces of fiber optic sensors including trapping in porous membranes, chemical bonding to silica-coupled silane molecules or organic membranes, and polymerizing the ligand onto a silica surface. The method chosen for ligand immobilization can affect response time, selectivity, sensitivity, and reversibility.

Among the diverse immobilization methods, the use of chemical bonding of the chromogenic ligand onto a polystyrene matrix appears to be very attractive since polystyrene can be readily converted to aminopolystyrene ${ }^{8,9,10}$ and then diazotized with nitrous acid (Figure 1). The resulting polymer-supported diazonium ion can provide a source of the required polymer-supported azo chromophore through a suitably chosen coupling reaction leading to a ligand of desired type. Most other immobilization methods do not appear to be suitable for the generation of immobilized diazonium ions as synthetic intermediates.

Chromogenic ligands of particular interest in this work are diarylthiocarbazones such as dithizone (diphenylthiocarbazone) and its analogs, which form highly colored complexes with mercury and lead. ${ }^{11.12}$ In this connection a number of methods are available for the synthesis of dithizone and related compounds. ${ }^{13,14}$ The method of 
greatest interest in connection with this project is the procedure of Hubbard and Scott ${ }^{15}$ based on earlier work by Bamberger, Padova, and Omerod ${ }^{16}$ since it provides a method for the conversion of an aromatic amine to the corresponding diarylthiocarbazone (Figure 2b).

The diarylthiocarbazones can be anchored onto a polystyrene matrix by coupling with a polystyrene-supported diazonium salt using a procedure reported by Chwastowska and Kosiarska (Figure 3). ${ }^{10}$ However in this case the coupling process introduces a new azo chromophore which might dilute the effect of the heavy metal to be detected on the visible spectrum. This difficulty can be avoided by chemically anchoring a diarylthiocarbazone functionality onto a polymer so that the polymer matrix become an integral part of the diarylthiocarbazone chromophore. Such an approach requires a sequence of reactions such as those depicted in Figures 2a and 4. In the first step a nitroformaldehyde arylhydrazone is prepared by coupling the corresponding arenediazonium salt with the nitromethane anion in a 1:1 ratio (Figure 2a). ${ }^{16}$ Subsequent coupling of the nitroformaldehyde arylhydrazone with the diazonium salt of polystyrene (Figure 1) can then give an unsymmetrical diarylnitroformazan in which one of the aryl groups is part of the polystyrene matrix (Figure 4). Such unsymmetrical diarylnitroformazans can be then converted to the corresponding unsymmetrical diarylthiocarbazones by the same methods as used for the symmetrical dithizones (Figure 4).14,15 This synthetic approach to the unsymmetrical diarylthiocarbazones through nitroformaldehyde arylhydrazones (Figure 4) has been developed by Pupko and Pel'kis ${ }^{17,18}$ but had not yet been adapted for the preparation of polymer-supported diarylthiocarbazones when the work described in this paper was initiated.

\section{Experimental}

\subsection{Materials}

Polystyrene SP5009 (1\% divinylbenzene crosslinking) and polystyrene SP5018 (2\% divinylbenzene crosslinking) were purchased from Advanced ChemTech. More highly crosslinked polystyrene macroreticular beads (copolymer XFS 4022 with $20 \%$ divinylbenzene) were obtained from Dow Chemical Company. The remaining reagents were purchased from standard suppliers.

\subsection{Synthesis of nitroformaldehyde $\beta$-naphthylhydrazone}

The $\beta$-naphthylamine hydrochloride ( 0.4 mole) was stirred overnight in a mixture of $100 \mathrm{~mL}$ of water and $120 \mathrm{~mL}$ of $\mathrm{HCl}$ and then diazotized with $28 \mathrm{~g}$ of $\mathrm{NaNO}_{2}$ dissolved in $60 \mathrm{~mL}$ of water at -5 to $-8^{\circ} \mathrm{C}$ using a cold bath of dry ice and o-xylene. The sodium salt of nitromethane was prepared in a separate vessel by combining 0.4 mole $(22 \mathrm{~mL})$ of 
nitromethane in $100 \mathrm{~mL}$ of absolute ethanol with $16 \mathrm{~g}$ of $\mathrm{NaOH}$ in $100 \mathrm{~mL}$ of water at -5 to $-8^{\circ} \mathrm{C}$. The resulting white precipitate of the sodium salt of nitromethane was dissolved in $50 \mathrm{ml}$ of water to give a yellow solution. This solution was added dropwise to the filtered diazonium salt solution kept at $-8^{\circ} \mathrm{C}$. The final mixture was stirred for $3 \mathrm{hr}$. The precipitate was filtered off and washed with water. The crude product was purified by dissolving in 5\% aqueous sodium hydroxide. After separation of the insoluble fraction the nitroformaldehyde arylhydrazone was precipitated with dilute hydrochloric acid $(0.25 M)$. Three such cleaning cycles were required to obtain reasonably pure product. The reaction yield was $42 \%$ based on the amine used in the synthesis. Air dried solid nitroformaldehyde $\beta$-naphthylhydrazone is orange and melts at $90-94^{\circ} \mathrm{C}$. It was characterized by infrared and ultraviolet-visible spectroscopy.

\subsection{Synthesis of di- $\beta$-naphthylnitroformazan}

$\beta$-Naphthylamine hydrochloride ( 0.4 mole) was stirred overnight in a mixture of $100 \mathrm{~mL}$ of water and $80 \mathrm{~mL}$ of $\mathrm{HCl}$ and then diazotized with $28 \mathrm{~g}$ of $\mathrm{NaNO}_{2}$ dissolved in $60 \mathrm{~mL}$ of water at -5 to $-8^{\circ} \mathrm{C}$ in a cold bath of dry ice and o-xylene. The filtered diazotized mixture was then combined with a cold aqueous solution of sodium acetate $(87 \mathrm{~g}$ in 150 $\mathrm{mL}$ of water). In a separate vessel the sodium salt of nitromethane was prepared by mixing at -5 to $-8^{\circ} \mathrm{C}$ solutions of 0.2 mole $(11 \mathrm{~mL})$ of nitromethane in $50 \mathrm{~mL}$ of absolute ethanol and $8 \mathrm{~g}$ of $\mathrm{NaOH}$ in $50 \mathrm{~mL}$ of water. The white precipitate of the sodium salt of nitromethane was dissolved in $50 \mathrm{~mL}$ of water to give a yellow solution. This solution was added dropwise into the diazonium salt solution kept at $-8^{\circ} \mathrm{C}$. The final mixture was stirred for $2 \mathrm{hr}$ at -5 to $-18^{\circ} \mathrm{C}$. The temperature was then gradually increased to -4 to $0^{\circ} \mathrm{C}$ for 2 $\mathrm{hr}$. The di- $\beta$-naphthylnitroformazan precipitated as a maroon solid which was separated by filtration and washed with water. The crude moist precipitate was purified by treatment with $150 \mathrm{~mL}$ of $50 \%$ acetic acid with gentle heat up to $40^{\circ} \mathrm{C}$ with constant stirring. The mixture was then cooled to room temperature, filtered, and washed with $100 \mathrm{~mL}$ of $10 \%$ acetic acid followed by water. The air-dried material was ground in a mortar with $200 \mathrm{~mL}$ of absolute ethanol. This mixture was brought to the boiling point with stirring and then filtered. The precipitate was washed with $50 \mathrm{~mL}$ of hot ethanol and finally air dried. The resulting maroon solid melts at $178-180^{\circ} \mathrm{C}$. The yields based on amine used in the synthesis were in the range 60 to $85 \%$. These products were characterized by infrared and ultraviolet-visible spectroscopy. 


\subsection{Synthesis of unsymmetrical phenyl- $\beta$-naphthylnitroformazan}

This unsymmetrical diarylnitroformazan was synthesized from nitroformaldehyde $\beta$-naphthylhydrazone and phenyldiazonium ion. The phenyldiazonium ion (5 mmoles) was prepared from aniline as described above and cooled to $-8^{\circ} \mathrm{C}$. The solution was buffered at this low temperature by adding a solution of $9.2 \mathrm{~g}$ of sodium acetate, $14 \mathrm{~mL}$ of acetic acid, and $20 \mathrm{~mL}$ of water to give a $\mathrm{pH}$ of 5 . A cold solution of 0.05 mmoles of nitroformaldehyde $\beta$-naphthylhydrazone in methanol was added dropwise and the mixture was stirred for $2 \mathrm{hr}$ at 0 to $+5^{\circ} \mathrm{C}$. The resulting diarylnitroformazan was separated by filtration and washed with deionized water and ethanol until the washings were colorless. The yield of crude material was $94 \%$.

\subsection{Preparation of di- $\beta$-naphthylthiocarbazide}

Di- $\beta$-naphthylnitroformazan (18 g) suspended in $200 \mathrm{~mL}$ of ethanol was treated with $100 \mathrm{~mL}$ of aqueous ammonium sulfide ( $20 \%$ by weight) for $1 \mathrm{hr}$ at room temperature. Gentle heat (up to $40^{\circ} \mathrm{C}$ ) was applied for $2 \mathrm{hr}$. The mixture was then poured into $500 \mathrm{~mL}$ of cold water and the precipitate was separated by filtration. The beige-yellow solid was washed with water and ethanol and then air dried. The yields of product were above $90 \%$.

\subsection{Preparation of di- $\beta$-naphthylthiocarbazone}

The di- $\beta$-naphthylthiocarbazide $(7.8 \mathrm{~g})$ was treated with $100 \mathrm{~mL}$ of $5 \%$ ethanolic potassium hydroxide solution for 15 minutes at room temperature to give a dark red solution which was then filtered. The clear filtrate was neutralized to $\mathrm{pH} \sim 6$ with dilute hydrochloric acid and $1 \mathrm{~L}$ of cold water was added. The mixture was stirred for $1 \mathrm{hr}$. The resulting precipitate was separated by filtration and washed with distilled water. Air-dried crude di- $\beta$-naphthylthiocarbazone was purified by three subsequent chloroform extractions using $150 \mathrm{~mL}$ of solvent each time. The combined chloroform solution was washed with three $100 \mathrm{~mL}$ portions of distilled water, the chloroform layer being removed each time to a clean separatory funnel. The washed chloroform solution was filtered and evaporated to $\sim 100 \mathrm{~mL}$ volume and dried overnight over magnesium sulfate. The solution was once more filtered and $100 \mathrm{~mL}$ of absolute ethanol was added. The precipitated di- $\beta$-naphthylthiocarbazone was filtered off and air dried.

\subsection{Air oxidation of di- $\beta$-naphthylthiocarbazide to di- $\beta$-naphthylthio-} carbazone in 1,2-dichloroethane

The di- $\beta$-naphthylthiocarbazide was dissolved in 1,2-dichloroethane in a twonecked round-bottomed flask placed on a heating mantle. A slow stream of air was bubbled 
through the solution which was brought to boiling temperature $\left(\sim 85^{\circ} \mathrm{C}\right)$. A condenser fitted to the flask reduced evaporation of the solvent. However it was necessary to add further portions of solvent periodically especially during long time oxidations using larger samples $(>1 \mathrm{~g})$. The color of the solution changed gradually after $\sim 3 \mathrm{hr}$ to a very intense greenblack. After the oxidation was complete, the solvent was evaporated. The crude di- $\beta$ naphthylthiocarbazone was purified by chloroform extraction in the same manner as previously described.

\subsection{Hydrogen peroxide oxidation of di- $\beta$-naphthylthiocarbazide to di- $\beta$-naphthylthiocarbazone}

A $1 \mathrm{~g}$ portion of di- $\beta$-naphthylthiocarbazide or a functionalized polymeric thiocarbazide was treated with $10 \mathrm{~mL}$ of $3 \%$ hydrogen peroxide solution for $15 \mathrm{~min}$ at ambient temperature. The resulting solid was separated by filtration, washed with water, and air dried.

\subsection{Preparation of nitro- and aminopolystyrenes}

A $30 \mathrm{~g}$-portion of the polystyrene was suspended in a mixture of acetic anhydride and acetic acid and cooled to $-4^{\circ} \mathrm{C}$. Nitric acid was slowly introduced and the mixture was stirred at low temperature $\left(\sim-4^{\circ} \mathrm{C}\right)$. After the reaction was completed the solids were filtered off, washed, and air dried. The nitration of polystyrene was also carried out in which the acetic acid-acetic anhydride mixture was substituted by sulfuric acid (samples 3-18, 3-20, 3-22, 3-24). The reaction conditions are listed in Table 1. The nitropolystyrenes were reduced to the corresponding aminopolystyrenes with stannous chloride in hydrochloric acid at room temperature or $90^{\circ} \mathrm{C}$ (see Table 1 ).

\subsection{Functionalization of diazotized aminopolystyrene with nitroform-} aldehyde $\beta$-naphthylhydrazone and its conversion to thiocarbazone.

A 0.5 to $10 \mathrm{~g}$-portion of aminopolystyrene was suspended in a mixture of hydrochloric acid and water cooled to $\sim-4^{\circ} \mathrm{C}$ and then diazotized with 0.1 mole of $\mathrm{NaNO}_{2}$ dissolved in $40 \mathrm{~mL}$ of distilled water. The mixture was stirred for $1 \mathrm{hr}$ to allow complete reaction. The resulting solid was separated by filtration, washed with cold water to remove an excess of acid, and then immediately transferred into a cold buffer solution of $36 \mathrm{~g}$ of sodium acetate, $40 \mathrm{~mL}$ of acetic acid, and $20 \mathrm{~mL}$ of water. The nitroformaldehyde arylhydrazone $(\sim 0.5$ to $1 \mathrm{~g})$ dissolved in $200 \mathrm{~mL}$ of ethanol was filtered and cooled to 0 $2^{\circ} \mathrm{C}$. This ethanolic solution was slowly added to the polymer suspension. The final mixture was stirred at -2 to $+4^{\circ} \mathrm{C}$ for $6 \mathrm{hr}$. The dark colored solid was separated and 
washed with water and then with ethanol until the filtrate was clear. In several cases Soxhlet extraction was used to minimize use of ethanol.

In the next step the functionalized polystyrene was treated with an aqueous solution of ammonium sulfide at room temperature for at least $3 \mathrm{hr}$. Thus a 1 to $10 \mathrm{~g}$-portion of functionalized polymer was treated with 20 to $100 \mathrm{~mL}$ of $20 \%$ aqueous ammonium sulfide as previously described for di- $\beta$-naphthylnitroformazan. A more rapid reaction was obtained with solutions also containing $5 \mathrm{ml}$ of $21 \%$ ammonium hydroxide .

\subsection{Anchoring of di- $\beta$-naphthylthiocarbazone to polystyrene (procedure of} Chwastowska and Kosiarska ${ }^{10}$ )

A portion of aminopolystyrene $(\sim 5 \mathrm{~g})$ suspended in a mixture of $120 \mathrm{~mL}$ of concentrated hydrochloric acid and $100 \mathrm{~mL}$ of water was cooled to about $-4^{\circ} \mathrm{C}$ and then diazotized with $18.6 \mathrm{~g}$ of sodium nitrite dissolved in $50 \mathrm{~mL}$ of water for $4 \mathrm{hr}$. Solids were filtered off, washed with cold water, and transferred into a cold acetate buffer solution prepared by dissolving $36.4 \mathrm{~g}$ of sodium acetate and $50 \mathrm{~mL}$ of acetic acid in $100 \mathrm{ml}$ of water. An acetone solution $(200 \mathrm{~mL})$ containing approximately $0.5 \mathrm{~g}$ of di- $\beta$-naphthylthiocarbazone was filtered and slowly added and the mixture was stirred for 4 to $18 \mathrm{hr}$. After the reaction was complete, the crosslinked polystyrene was washed with water, then with acetone to remove unreacted di- $\beta$-naphthylthiocarbazone, and air-dried. Attempts to separate unreacted di- $\beta$-naphthylthiocarbazone from the uncrosslinked polymer met with difficulty owing to significant acetone solubility of the polymer itself. Therefore a water-acetone mixture (3:1) rather than pure acetone was used to wash these samples. Air-dried samples obtained from the uncrosslinked polymer did not appear to be homogeneous.

\subsection{Spectroscopic methods}

The infrared spectra were recorded on a Perkin Elmer 1600 Series FT-IR infrared spectrometer using $\mathrm{KBr}$ disks. The electronic spectra of chloroform solutions were recorded on a Hewlett Packard Model 8452A Diode Array Spectrophotometer. The electronic spectra of solid samples were taken in Nujol mulls placed between two methacrylate ultraviolet grade plates. Proton nuclear magnetic resonance spectra of nitroformaldehyde arylhydrazones, diarylnitroformazans and the corresponding diarylthiocarbazones were recorded in $\mathrm{CDCl}_{3}$ solutions on a Bruker $\mathrm{AC}-300$ spectrometer operating at $300 \mathrm{MHz}$ for protons. However since most of polymers used in the preparation of the functionalized polystyrenes are insoluble in organic solvents, solution NMR spectra of these polymers could not be obtained. 


\section{Results and Discussion}

\subsection{Synthesis of nitroformaldehyde $\beta$-naphthylhydrazone, di- $\beta$-naphthyl- formazan, and unsymmetrical phenyl- $\beta$-naphthylnitroformazan.}

The synthetic method reported by Pupko and Pel'kis ${ }^{16}$ (Figure 2) was investigated in which 1 mole of aryldiazonium salt was coupled with 1 mole of the sodium salt of nitromethane to form the corresponding nitroformaldehyde arylhydrazone. By using this method nitroformaldehyde arylhydrazones were synthesized in which the aryl group was phenyl, 2,4,6-trimethylphenyl and $\beta$-naphthyl. However, the phenyl and 2,4,6-trimethylphenyl derivatives were quite unstable at room temperature and decomposed over a period of several days. Therefore we concentrated our efforts on the more stable nitroformaldehyde $\beta$-naphthylhydrazone .

Since the paper by Pupko and Pel'kis ${ }^{16}$ did not describe adequately the synthesis of nitroformaldehyde $\beta$-naphthylhydrazone, the details of the preparative procedure needed to be worked out. In our initial experiments based on the Pupko and Pel'kis procedure ${ }^{16} 0.1$ mole of $\beta$-naphthylamine hydrochloride was suspended in water and then diazotized with the stoichiometric amount of $\mathrm{NaNO}_{2}$ with cooling to -5 to $-8^{\circ} \mathrm{C}$. The sodium salt of nitromethane $(0.1$ mole) was prepared separately. The aryldiazonium salt solution was added dropwise to the nitromethane solution at -5 to $-8^{\circ} \mathrm{C}$ and the mixture was stirred for $4 \mathrm{hr}$. Several cleaning cycles were required to obtain reasonably pure product and the final yield was relatively poor not exceeding $20 \%$. We found that this coupling reaction is strongly $\mathrm{pH}$-dependent and is not a smooth reaction since considerable amounts of tarry byproducts are produced, especially when aniline and 2,4,6-trimethylaniline are used as starting materials. The main side product of the reaction was the corresponding diarylnitroformazan. In a number of experiments we found that if the reaction conditions suggested by Pupko and Pel'kis ${ }^{16}$ were used, the final $\mathrm{pH}$ of the mixture was about 2.5 and considerable diarylnitroformazan side product was produced at the beginning of the coupling reaction when the mixture still was very basic. Our modification of the Pupko and Pel'kis procedure ${ }^{16}$ using an excess of acid for the preparation of the aryldiazonium salt and reversing the order of mixing so that the nitromethane solution was added to the aryldiazonium solution rather than vice versa was found to suppress significantly the formation of the diarylnitroformazan side product by keeping the $\mathrm{pH}$ low during the coupling reaction. Such modified conditions were used for synthesis of nitroformaldehyde $\beta$-naphthylhydrazone on a large scale.

The di- $\beta$-naphthylnitroformazan as well as the diphenyl and di(2,4,6-trimethylphenyl) analogues were synthesized according to the Hubbard procedure ${ }^{15}$ which is based 
on the coupling of 2 moles of the diazonium salt with 1 mole of the sodium salt of nitromethane. This method was found to give very reproducible results with good yields of the diarylnitroformazans.

The unsymmetrical diarylnitroformazans were synthesized in satisfactory yields from the corresponding nitroformaldehyde arylhydrazone and phenyldiazonium ion using the Pupko and Pel'kis procedure. ${ }^{17,18}$ All samples prepared were characterized by spectroscopic methods, mainly infrared and ultraviolet-visible spectra.

These three $\beta$-naphthylnitroformazans exhibit distinct electronic and infrared spectra which can be easily identified. Thus for di- $\beta$-naphthylnitroformazan the main absorption is observed at $488 \mathrm{~nm}$ whereas for nitroformaldehyde $\beta$-naphthylhydrazone the maximum occurs at $412 \mathrm{~nm}$. The main absorbance maxima of the unsymmetrical diarylnitroformazans are distinctly different from those of the symmetrical analogs occurring at 338 and 464-470 $\mathrm{nm}$. The same relationship was observed for phenyl and 2,4,6-trimethylphenyl analogues.

The infrared spectrum of nitroformaldehyde $\beta$-naphthylhydrazone consists of sets of bands in the $600-1700 \mathrm{~cm}^{-1}$ region. The most intense absorption occurs between 1050 and $1400 \mathrm{~cm}^{-1}$ where several bands with shoulders are observed. The di- $\beta$-naphthylnitroformazan exhibits a very poor infrared spectrum dominated by bands at 1271,1343 and $1550 \mathrm{~cm}^{-1}$ The unsymmetrical phenyl- $\beta$-naphthylformazan exhibits an infrared spectrum similar to nitroformaldehyde $\beta$-naphthylhydrazone with some shifts in band positions to 1279,1350 and $1543 \mathrm{~cm}^{-1}$, respectively.

\subsection{Formation of di- $\beta$-naphthylthiocarbazide}

The original procedure for converting diarylnitroformazans to the corresponding diarylthiocarbazones used a two-step reaction (Figure $2 b$ ). In the first step the diarylnitroformazan was converted into the corresponding diarylthiocarbazide by treatment with gaseous ammonia and hydrogen sulfide in ethanol ${ }^{14,15}$ followed by oxidation to the corresponding diarylthiocarbazone. Our syntheses of di- $\beta$-naphthylthiocarbazide used a modified version of this reaction with commercial aqueous ammonium sulfide. This procedure allowed us to avoid the inconvenience of using gaseous $\mathrm{NH}_{3}$ and $\mathrm{H}_{2} \mathrm{~S}$ and was previously used for the synthesis of some dithizone derivatives but not di- $\beta$-naphthylthiocarbazone. Therefore it was necessary to work out the optimum conditions of the reaction. In this connection several batches of di- $\beta$-naphthylthiocarbazone were synthesized and characterized by spectroscopic methods.

The infrared spectra of two samples of di- $\beta$-naphthylthiocarbazone synthesized from the same starting diarylnitroformazan are almost identical confirming the reproducibility of this synthetic method. Some shifts in the band position $\sim+4 \mathrm{~cm}^{-1}$ and small 
changes in the relative intensities can be ascribed to the different levels of impurities. In general the infrared spectra of samples of di- $\beta$-naphthylthiocarbazide consist of bands mainly in the $600-800,1150-1300$ and $1400-1700 \mathrm{~cm}^{-1}$ regions. The absorption bands between $1200-1300 \mathrm{~cm}^{-1}$ indicate the presence of the $-\mathrm{SH}$ group. The bands at 1270 and $1343 \mathrm{~cm}^{-1}$ present in the spectrum of the starting di- $\beta$-naphthylnitroformazan completely vanished upon conversion to the corresponding diarylthiocarbazone and were replaced by sets of bands with maxima at 1180,1220 and $1250 \mathrm{~cm}^{-1}$. Additional infrared bands appeared at $1470,1510,1560$ and $1600 \mathrm{~cm}^{-1}$.

The diarylthiocarbazides are not very stable in air as they readily undergo oxidation to the corresponding diarylthiocarbazones. Our samples were exposed to air for different periods of time before the infrared spectra were registered and thus are probably contaminated with oxidation products to varying extents.

The electronic spectra taken on freshly synthesized di- $\beta$-naphthylthiocarbazide and samples exposed to air for several days show differences indicating that the diarylthiocarbazides are not very stable in air as they readily undergo oxidation to the corresponding diarylthiocarbazones. The fresh synthesized sample exhibits a major maximum at $256 \mathrm{~nm}$ with low intensity absorptions at 416 and $650 \mathrm{~nm}$. Upon exposure to air for 3 days the band at $650 \mathrm{~nm}$ increases in intensity. This band is characteristic for di- $\beta$-naphthylthiocarbazone. $11,15,19,20$

\subsection{Oxidation of di- $\beta$-naphthylthiocarbazide to di- $\beta$-naphthylthiocarbazone}

A critical step in the preparation of the diarylthiocarbazones is the oxidation of the corresponding diarylthiocarbazides. The original method 14,15 for preparation of diarylthiocarbazones used oxidation by air in strongly basic ethanolic $\mathrm{KOH}$ solution. This is actually a disproportionation reaction with a maximum yield of $50 \%$ of the diarylthiocarbazone. It was found 21 that at least in some cases the yields of diarylthiocarbazones could be increased to $80-90 \%$ by air oxidation in a neutral organic solvent. Both methods were used for oxidation of diarylthiocarbazides to the corresponding diarylthiocarbazones. We have found that the yield of di- $\beta$-naphthylthiocarbazone yield by oxidation/disproportionation in ethanolic $\mathrm{KOH}$ solution depends on reaction time with longer reaction times leading to lower yields. We thus recommend a reaction time of only $15 \mathrm{~min}$ for the $\mathrm{KOH}$ oxidation/disproportionation.

The infrared spectra of the purified products confirm formation of di- $\beta$-naphthylthiocarbazone. Samples treated with potassium hydroxide for longer times exhibit additional bands and changes in the relative intensity patterns. Oxidation with air in a chlorinated solvent (e.g., 1,2-dichloroethane) was found to produce much purer products 
in higher yields but required longer reaction times. In a sample oxidized for $4 \mathrm{hr}$ the infrared bands of unreacted di- $\beta$-naphthylthiocarbazide were still observed in addition to the bands characteristic for di- $\beta$-naphthylthiocarbazone indicating incomplete oxidation. Such bands vanished from the infrared spectrum of samples oxidized for longer times. Attempts to substitute acetone for the chlorinated solvent in the air oxidation procedure failed. The infrared spectrum of the solid separated from acetone after aeration corresponds to unreacted di- $\beta$-naphthylthiocarbazide. The reason for this behavior is not clear. It can arise from the lower solubility of di- $\beta$-naphthylthiocarbazide in acetone compared to 1,2dichloroethane as was previously observed for dithizone derivatives ${ }^{21}$ or simply from the lower boiling temperature of acetone $\left(56^{\circ} \mathrm{C}\right.$ versus $84^{\circ} \mathrm{C}$ for 1,2 -dichloroethane). Oxidation of di- $\beta$-naphthylthiocarbazide with dilute hydrogen peroxide produced a dark brown solid that exhibited an infrared spectrum similar to di- $\beta$-naphthylthiocarbazone but with a different pattern of relative intensities. Moreover an additional relatively strong band around $1022 \mathrm{~cm}^{-1}$ was observed suggesting the presence of a sulfoxide group..$^{22}$ On the other hand sulfonic acids derivatives were previously identified as oxidation products of dithizone and their infrared spectra also exhibit such a band. ${ }^{23}$ In any case our sample obtained by hydrogen peroxide oxidation exhibited a different electronic spectrum and was completely inactive in reactions with mercury and lead cations.

In order to confirm formation of di- $\beta$-naphthylthiocarbazone in the oxidation of di- $\beta$-naphthylthiocarbazide either in potassium hydroxide solution or a chlorinated solvent, the electronic spectra were obtained in chloroform solution. In general the electronic spectra of the di- $\beta$-naphthylthiocarbazone samples exhibited a strong absorption maximum around $650 \mathrm{~nm}$ that is consistent with literature data for di- $\beta$-naphthylthiocarbazone. $11,15,24,25$ This band is shifted to lower wavenumbers upon complexation with lead and mercuric cations to $\sim 540$ and $\sim 510 \mathrm{~nm}$, respectively. Such changes are consistent with reported electronic spectra. $11,15,19,20,23,25$

\subsection{Preparation of aminopolystyrene}

We studied the functionalization of the following three samples of commercially available polystyrenes of different particle sizes and crosslinked with different amounts of divinylbenzene (DVB).

(1) Polystyrene SP5009 with a 100-200 mesh particle size and containing 1\% DVB.

(2) Polystyrene SP5018 with a 200-400 mesh particle size and containing 2\% DVB.

(3) Copolymer XFS 4022 consisting of beads and containing 20\% DVB.

We also studied a sample of commercially available uncrosslinked polystyrene (Polystyrene MW 45,000) in form of crushed plates. 
The samples of crosslinked polystyrene with different divinylbenzene (DVB) contents and different particle sizes as well as the sample of uncrosslinked polystyrene as suspensions were nitrated either with nitric acid in a mixture of acetic anhydride and acetic acid according to the published procedures ${ }^{8,9}$ or in the standard sulfuric acid medium frequently used for nitrations of benzenoid derivatives (samples 3-18, 3-20, 3-22, 3 24 as listed in Table 1). The samples of the resulting nitropolystyrene were then reduced to the corresponding aminopolystyrenes using stannous chloride in hydrochloric acid solution (Table 1).

In order to follow changes in the polymers after nitration and reduction infrared spectra of starting materials were recorded. The infrared spectra of starting polystyrenes were found to be similar. Some changes in the relative intensity of bands were noticeable presumably owing to the different DVB content. The uncrosslinked polymer was found to exhibit a poor spectrum. A set of bands between 1400 and $1700 \mathrm{~cm}^{-1}$ was found to be more intense in the crosslinked polymers.

Several batches of nitropolystyrene were prepared (Table 1). An initial batch (sample 1-16A) was synthesized using the method of King and Sweet ${ }^{9}$ including purification with different mixtures of organic solvents. The materials were then washed with pure water to remove acids following by ethanol. The degree of nitration was estimated from the infrared spectra of the solid nitropolystyrenes, which were yellow solids exhibiting infrared bands around 1520 and $1345 \mathrm{~cm}^{-1}$ not present in the original polystyrenes indicative of aromatic nitro groups. The $1345 \mathrm{~cm}^{-1}$ band overlaps with the $\sim 1320$ and $1370 \mathrm{~cm}^{-1}$ bands of polystyrenes. The product of the nitration in THF solution (sample 3-2) exhibited very low intensity bands in this region. The intensity of these bands increased for samples synthesized in a sulfuric acid medium. The degree of nitration was found to depend on the particle size of solid rather than the divinylbenzene content with smaller particles leading to lower degrees of nitration.

The nitropolystyrenes were reduced to the corresponding aminopolystyrenes using stannous chloride in hydrochloric acid at room temperature or $90^{\circ} \mathrm{C}$ (Table 1). The uncrosslinked nitropolystyrene can be completely reduced to the corresponding aminopolystyrene by increasing the reduction time at room temperature. In the infrared spectra of the aminopolystyrenes the bands at 1345 and $1520 \mathrm{~cm}^{-1}$ assigned to nitro groups are no longer observable. The crosslinked nitropolystyrenes are more resistant towards reduction so that higher temperatures are recommended for complete reduction to aminopolystyrenes. However the rate of reduction depends on the particle size of the solid rather than the DVB content as we have previously observed for the nitration reaction discussed above. For the 
partially reduced samples the infrared bands at $\sim 1520 \mathrm{~cm}^{-1}$ and $\sim 1345 \mathrm{~cm}^{-1}$ are still observed but in lower intensities.

\subsection{Functionalization of diazotized aminopolystyrene with nitroformaldehyde $\beta$-naphthylhydrazone}

Several batches of each type of aminopolystyrene functionalized with nitroformaldehyde $\beta$-naphthylhydrazone were prepared and characterized by infrared and ultraviolet spectroscopy. In a typical experiment aminopolystyrene was diazotized with an excess of sodium nitrite in hydrochloric acid and then coupled with the nitroformaldehyde $\beta$-naphthylhydrazone to give a polymer-supported diarylnitroformazan (Figure 4) following the reaction pathway described earlier for synthesis of unsymmetrical diarylnitroformazans. ${ }^{17,18}$ The best results in the synthesis of unsupported diarylnitroformazans were obtained when the reaction mixture was buffered to $\mathrm{pH}$ about 4 to 5 as noted above. However the diazotization reaction required a very low $\mathrm{pH}$ of $\sim 0-1$. Therefore in order to avoid neutralization of excess acid with alkali the coupling procedure was modified. The aminopolystyrene diazotized at low $\mathrm{pH}$ was quickly filtered off from the reaction mixture, washed generously with cold water, and immediately transferred into a cold buffer solution of sodium acetate and acetic acid followed by coupling with the nitroformaldehyde arylhydrazone dissolved in ethanol. The dark colored solids were separated and washed with water to remove acetates followed by ethanol to remove excess nitroformaldehyde arylhydrazone. In several cases Soxhlet extraction was used to minimize the use of ethanol.

The electronic spectra of these products showed a very broad absorption in the 400$700 \mathrm{~nm}$ range without distinct maxima similar to the spectra of solid diarylnitroformazans. The infrared spectra of functionalized polymers in general exhibit changes in the relative intensities of bands in the $1100-1700 \mathrm{~cm}^{-1}$ range as well as new bands at 1273, 1320, $1520,1541,1628$ and $1653 \mathrm{~cm}^{-1}$ compared to the starting aminopolystyrene. Those absorptions can be observed as distinct bands or as shoulders depending on the degree of functionalization which would depend of course on the number of active sites on the polymer generated during diazotization. The positions of new bands or shoulders in general are comparable with the those of most intense bands for di- $\beta$-naphthylnitroformazan and the corresponding unsymmetrical phenyl- $\beta$-naphthylnitroformazan.

In the next step the functionalized polystyrenes were treated with an aqueous solution of ammonium sulfide at room temperature for at least $3 \mathrm{hr}$. In. some cases this reaction was carried out for $18 \mathrm{hr}$ in order to observe visually a color change to beige in accord with expectations based on the color of the corresponding di- $\beta$-naphthylthio- 
carbazide. However in many cases the products after treatment with aqueous ammonium sulfide displayed dark green or gray colors similar to solid diarylthiocarbazones.

After treatment with aqueous ammonium sulfide the infrared spectra of the functionalized polystyrenes exhibited bands characteristic of polystyrene and some shifts in the band positions compared to the $\beta$-naphthylnitroformazan modified polymers. The most significant difference is that the band at $\sim 1273 \mathrm{~cm}^{-1}$ originally present in the infrared spectra of polystyrenes functionalized with nitroformaldehyde $\beta$-naphthylhydrazone vanished after treatment with ammonium sulfide similar to observations with unsupported di- $\beta$-naphthylnitroformazan indicating conversion of the supported diarylnitroformazan functionalities to the corresponding diarylthiocarbazide functionalities.

The green or olive color of the solid products suggests that the supported diarylthiocarbazides were at least partially oxidized to the corresponding diarylthiocarbazones. Therefore we decided to test the products at this stage of the reaction sequence with heavy metal cations. In this connection these solids were shaken vigorously with aqueous solutions of $\mathrm{Pb}^{2+}$ and $\mathrm{Hg}^{2+}$. The green or olive colors of these solids were replaced with reddish or pinkish colors indicating metal complexation. These metal-containing polymers were separated and air dried and their infrared spectra were recorded giving the following results:

Lead-containing polymer: $672,752,834,905,1016,1067,1160,1178$, low intensity $1230,1341,1438,1498,1578$ with several shoulders, $1654 \mathrm{~cm}^{-1}$.

Mercury-containing polymer: $675,752,829,903,1015,1054,1154,1268,1326,1340$, $1432,1465,1471,1508,1560,1576,1654 \mathrm{~cm}^{-1}$.

It was not surprising that in these experiments only low intensity bands corresponding to the metal complexes were observed in addition to those of the diarylthiocarbazide since the degree of the oxidation of the functionalized polymer is presumably very low. However some changes in the infrared spectra are visible. The infrared band around $1382 \mathrm{~cm}^{-1}$ in the metal-free polymers vanished from spectra of samples treated with the heavy metals. Instead a set of bands at 1320,1342 and $1360 \mathrm{~cm}^{-1}$ were observed. The bands at $\sim 1022,1067,1179,1490$, and $1597 \mathrm{~cm}^{-1}$ for supported $\beta$-naphthyl species are shifted to 1016 and 1015, 1059 and 1054, 1160 and 1154,1500 and 1474, 1578 and $1576 \mathrm{~cm}^{-1}$ for samples treated with $\mathrm{Pb}^{+2}$ and $\mathrm{Hg}^{+2}$, respectively. Such changes in the infrared spectra are consistent with literature data ${ }^{19,26,27,28,29,30}$ concerning formation of heavy metal complexes of diphenylthiocarbazone and di- $\beta$-naphthylthiocarbazone.

Since there are no data in the literature concerning oxidation of polymer-supported diarylthiocarbazides to the corresponding diarylthiocarbazones, it was necessary to find suitable conditions for these oxidations. In this connection the polymer-supported 
diarylthiocarbazides were oxidized using methods described above including treatment with ethanolic $\mathrm{KOH}$, air oxidation in a chlorinated solvent (1,2-dichloroethane), and treatment with dilute hydrogen peroxide.

Polymer-supported diarylthiocarbazides were expected to be more difficult to oxidize than unsupported diarylthiocarbazides. Therefore the polymer-supported diarylthiocarbazides were allowed to react with potassium hydroxide solution for 1 or $2 \mathrm{hr}$ instead of the $15 \mathrm{~min}$ used for di- $\beta$-naphthylthiocarbazide. The infrared spectra of these products indicated no significant differences between those two samples, which is not surprising since diarylthiocarbazides and diarylthiocarbazones absorb in similar regions. However some changes in the relative intensities and band positions are observed, especially around 1152,11791342 and $1654 \mathrm{~cm}^{-1}$ indicative of thiocarbazone formation. Air oxidation in 1,2-dichloroethane appeared to give the same product. Oxidation with dilute hydrogen peroxide produced an almost black solid. The infrared spectra exhibited changes in the $1000-1340 \mathrm{~cm}^{-1}$ region with domination of a band around $1152 \mathrm{~cm}^{-1}$

Presently available methods do not allow a quantitative comparison of supported diarylthiocarbazones obtained by different oxidation methods. Therefore these products were tested in reactions with heavy metals $\left(\mathrm{Pb}^{2+}\right.$ and $\left.\mathrm{Hg}^{2+}\right)$. In this connection all samples were found to give a positive reaction with $\mathrm{Pb}^{2+}$ and $\mathrm{Hg}^{2+}$. There were changes in the infrared spectra of such samples treated with heavy metals similar to those discussed above.

Both $\mathrm{KOH}$ oxidation/disproportionation and air oxidation were found to give similar products based on infrared spectroscopy and reactions with heavy metal cations. However owing to the properties of uncrosslinked polystyrene, the $\mathrm{KOH}$ oxidation/disproportionation was chosen for further experiments.

All types of functionalized polystyrenes were converted into the corresponding polystyrene-supported diarylthiocarbazides. The longest time required to observe color changes upon treatment of the polystyrene-supported diarylnitroformazan with aqueous ammonium sulfide occurred with samples prepared from polystyrene containing 2\% DVB. Furthermore, treatment of these polystyrene-supported diarylthiocarbazides with potassium hydroxide gave no observable color changes; however the resulting products appeared to react with heavy metal cations giving pinkish to violet reflections in the solutions. However, such reactions were not spontaneous requiring some time (up to $18 \mathrm{hr}$ ). to develop these color changes. For polystyrene-supported dithizones made from polystyrene containing $2 \%$ of DVB, these color changes with heavy metals could not be observed visually. In experiments using different polystyrenes it was found that the reactions of polystyrene-supported diarylnitroformazans with aqueous ammonium sulfide in basic 
ethanolic suspension were more rapid than those in neutral solution giving observable color changes after $3 \mathrm{hr}$ of stirring. All samples appeared to react with heavy metal cations $\left(\mathrm{Pb}^{2+}\right.$ and $\mathrm{Hg}^{2+}$ ) but a long time up to 3 days was required to observe the color changes.

\subsection{Anchoring of di- $\beta$-naphthylthiocarbazone to polystyrene using the pro- cedure of Chwastowska and Kosiarska}

The second approach to the synthesis of spectroscopic indicators for heavy metal cations is based on work of Chwastowska and Kosiarska ${ }^{10}$ in which previously synthesized diarylthiocarbazones are anchored to the diazotized aminopolystyrene through an additional coupling reaction (Figure 3). Several batches of polymers functionalized in this way were synthesized from the corresponding aminopolystyrene derived from uncrosslinked as well as crosslinked polystyrene. The products of this reaction are brown or black solids, which were characterized by infrared and ultraviolet spectroscopy.

The electronic spectra of polystyrenes functionalized by the method of Chwastowska and Kosiarska ${ }^{10}$ display a maximum around $268 \mathrm{~nm}$ and a very flat, broad absorption between $400-700 \mathrm{~nm}$. The solid di- $\beta$-naphthylthiocarbazone itself in a Nujol mull exhibits absorptions at 270,340 and $600-750 \mathrm{~nm}$ but the maxima cannot be estimated precisely. In the infrared spectra of polystyrenes functionalized by the method of Chwastowska and Kosiarska ${ }^{10}$ new bands noticeable as shoulders around 1200, 1383, 1475 and $1583 \mathrm{~cm}^{-1}$ indicate anchored di- $\beta$-naphthylthiocarbazone.

The di- $\beta$-naphthylthiocarbazone-supported polystyrenes functionalized by the method of Chwastowska and Kosiarska ${ }^{10}$ were tested in reactions with $\mathrm{Pb}^{+2}$ and $\mathrm{Hg}^{+2}$ cations in aqueous solution. In this connection several $\mathrm{mg}$ of modified polymer were shaken with aqueous solutions of $\mathrm{Pb}^{+2}$ and $\mathrm{Hg}^{+2}$ cations for several minutes. The resulting suspensions exhibited pink and violet-red reflections in contrast to the corresponding metalfree polymers. The solids were filtered off, washed with water, and air dried. The amounts of solids were not sufficient to obtain reasonable electronic spectra in the solid state but allowed us to obtain their infrared spectra.

The most significant differences in the infrared spectra of di- $\beta$-naphthylthiocarbazone-supported polystyrenes functionalized by the method of Chwastowska and Kosiarska ${ }^{10}$ upon treatment with heavy metals were observed in the $1100-1600 \mathrm{~cm}^{-1}$ region. Thus the infrared band around $1382 \mathrm{~cm}^{-1}$ vanished from spectra of samples treated with $\mathrm{Pb}^{+2}$ and $\mathrm{Hg}^{+2}$. Instead a set of bands around 1310,1341 , and $1360 \mathrm{~cm}^{-1}$ was observed. The bands at $\sim 1152,1474$ and $1583 \mathrm{~cm}^{-1}$ for anchored di- $\beta$-naphthylthiocarbazone were shifted to 1176 and $1173 \mathrm{~cm}^{-1}, 1491$ and $1486 \mathrm{~cm}^{-1}$, and 1594 and 1597 $\mathrm{cm}^{-1}$ for $\mathrm{Pb}^{+2}$ and $\mathrm{Hg}^{+2}$ treated samples, respectively. Such changes in the infrared 
spectra are consistent with literature data concerning formation of metal dithizonates. ${ }^{19,26,27,28,29,30}$

We were uncertain if chemically anchored or unwashed physically adsorbed di- $\beta$-naphthylthiocarbazone was responsible for the color reactions with heavy metal cations in di- $\beta$-naphthylthiocarbazone-supported polystyrenes functionalized by the method of Chwastowska and Kosiarska. ${ }^{10}$ Therefore we prepared samples containing $1 \%$ by weight of the diarylthiocarbazone by making a tetrahydrofuran solution containing both the pure uncrosslinked polymer and di- $\beta$-naphthylthiocarbazone and allowing this solution to evaporate at room temperature in a big Petri dish. After evaporating overnight a polystyrene thick film was obtained. This film had the characteristic dark green color of the di- $\beta$-naphthylthiocarbazone ligand but did not undergo color changes with $\mathrm{Pb}^{+2}$ and $\mathrm{Hg}^{+2}$ even after 3 days. The infrared spectrum shows only changes in the relative intensities of bands owing to low loading. Similar results were obtained by using polyvinylchloride (PVC) rather than polystyrene films containing di- $\beta$-naphthylthiocarbazone. A very thin PVC film prepared by coating a very dilute solution on a large surface exhibited an infrared spectrum similar to a pure PVC matrix with some shifts in band positions. Thus the band at $\sim 1097 \mathrm{~cm}^{-1}$ in PVC is shifted to $1064 \mathrm{~cm}^{-1}$ for the film and a shoulder at $\sim 1131 \mathrm{~cm}^{-1}$ can be observed. The electronic spectra of the modified PVC film exhibited absorptions at 328 and $650 \mathrm{~nm}$ characteristic of pure di- $\beta$-naphthylthiocarbazone. Samples prepared in this way appeared to react with heavy metal cations $\left(\mathrm{Pb}^{+2}\right.$ and $\left.\mathrm{Hg}^{+2}\right)$ after 3 days.

\section{Summary}

This work demonstrates a method for chemical immobilization of a diarylthiocarbazone unit onto a polystyrene matrix using the coupling of nitroformaldehyde $\beta$-naphthylhydrazone with diazotized aminopolystyrene followed by treatment with aqueous ammonium sulfide and oxidation. This method has been used to prepare samples of polystyrene-supported diarylthiocarbazones which undergo distinctive color changes in $0.005 \mathrm{M}$ aqueous $\mathrm{Pb}^{2+}$ and $\mathrm{Hg}^{2+}$. Materials of this type are potentially useful as chromogenic ligands in fiber optic sensors for heavy metal detection.

\section{Acknowledgment}

We are indebted to the U. S. Department of Energy for support of this work through the Westinghouse Savannah River Corporation and the Education Research, and Development Association of Georgia Universities. We would like to acknowledge helpful 
discussions with Dr. Patrick O'Rourke, currently of EquaTech International, New Ellenton, South Carolina. 


\section{Literature References}

[1] J. F. Adler, D. C. Ashworth, R. Narayanaswamy, R. E. Moss, I. O. Sutherland, An Optical Potassium Ion Sensor, Analyst, 1978, 112, 1191-1192.

[2] W. A. de Oliveira, R. Narayanaswamy, A Flow-Cell Optosensor for Lead Based on Immobilized Dithizone, Talanta, 1992, 39, 1499-1503.

[3] D. J. Edlund, D. T. Friesen, W. K. Miller, C. A. Thornton, R. L. Wedel, G. W. Rayfield, J. R. Lowell, Thin-film Polymeric Sensors for Detection and Quantification of Multivalent Metal Ions, Sensors and Actuators B, 1993, 10, 185-190.

[4] R. Czolk, J. Reichert, H. J. Ache, An Optical Sensor for the Detection of Heavy Metal Ions, Sensors and Actuators B, 1992, 7, 540-543.

[5] P. V. Lambeck, Integrated Opto-chemical Sensors, Sensors and Actuators $B$, 1992, 8, 103-116.

[6] A. Morales-Bahnik, R. Czolk, J. Reichert, H. J. Ache, An Optochemical Sensor for $\mathrm{Cd}(\mathrm{II})$ and $\mathrm{Hg}(\mathrm{II})$ Based on a Porphyrin Immobilized on Nafion ${ }^{\circledR}$ Membranes, Sensors and Actuators B, 1993, 13-14, 424-426.

[7] G. Frishman, G. Gabor, Surface Characteristics of Optical Chemical Sensors, Sensors and Actuators B, 1994, 17, 227-232.

[8] R. E. Buckles, M. P. Bellis, o-Nitrocinnamaldehyde, Organic Syntheses, Coll. Vol.IV, Wiley, New York, 1963, p.722.

[9] R. B. King, E. M. Sweet, Polymer-Anchored Cobalt (In) Tetraarylporphyrin Catalysts for the Conversion of Quadricyclane to Norbornadiene in a Solar Energy Storage System, J. Org. Chem., 1979, 44, 385-391.

[10] J. Chwastkowska, E. Kosiarska, Synthesis and Analytical Characterization of a Chelating Resin Loaded with Dithizone, Talanta, 1988, 35, 439-442.

[11] E. B. Sandell, Diphenylthiocarbazone, in Photometric Determination of Traces of Metals, Wiley-Interscience, New York, 1978, Chapter 6G, pp. 597-647.

[12] M. M. Harding, The Crystal Structure of the Mercury Dithizone Complex, $J$. Chem. Soc., 1958, 4136-4143.

[13] I. B. Suprumovich, Preparation of Dinaphthylthiocarbazone and its Metal Salts, $J$. Gen. Chem. U. S. S. R., 1938, 8, 839-843.

[14] E. Bamberger, R. Padova, E. Omerod, Über Nitro- and Amino-formazyl, Liebigs Ann., 1926, 260-307.

[15] D. M. Hubbard, E. W. Scott, Synthesis of Di-beta-naphthylthiocarbazone and Some of its Analogs, J. Am. Chem. Soc., 1943, 65, 2390-2393. 
[16] L. S. Pupko, N. Berzina, P. S. Pel'kis, The Synthesis of Substituted Phenylhydrazones of Nitroformaldehyde, Zhur. Obshch. Khim., 1963, 33, 2217-2220.

[17] L. S. Pupko, P. S. Pel'kis, Synthesis and Investigation of the Properties of Unsymmetrical Derivatives of Thiocarbazone, Zhur. Obshch. Khim., 1954, 24, 1640-1645.

[18] L. S. Pupko, P. S. Pel'kis, Synthesis and Investigation of Unsymmetrical Diarylthiocarbazones with Halo and Carboxy Substituents, Zhur. Org. Khim., 1965, 1, 735-738.

[19] H. M. N. H. Irving, Dithizone, Analytical Science Monograph The Chemical Society, London, 1977.

[20] R. J. DuBois, S. B. Knight, Some Properties of the Trace Heavy Metals Spectrophotometric Reagent Di- $\beta$-Naphthylthiocarbazone, Anal. Chem., 1964, $36,1313-1316$.

[21] A. T. Hutton, Studies on the Existence of a Tautomeric Equilibrium in Solutions of the Analytical Reagent Dithizone, Polyhedron, 1987, 6, 13-23.

[22] R. M. Silverstein, G. C. Bassler, T. C. Morrill, Spectrometric Identification of Organic Compounds, 4th Edition, Wiley, New York, 1981, p. 114.

[23] H. M. N. H. Irving, A. M. Kiwan, D. C. Rupainwar, S. Sahota, Studies with Dithizone. Part XXV. The Deterioration of Stock Solutions and the Identification of Two Oxidation Products, Anal. Chim. Acta, 1971, 56, 205-220.

[24] H. M. N. H. Irving, D. C. Rupainwar, S. Sahota, Studies with Dithizone. Part XIV. A New Oxidation Product of Dithizone, Anal. Chim. Acta, 1969, 45, 249254.

[25] K. S. Math, Q. Fernando, H. Freiser, Formation Constants of Nickel(II) and Zinc(II) Complexes of Dithizone and Related Compounds, Anal. Chem., 1964, $36,1762-1767$.

[26] A. M. Kiwan, A. Y. Kassim, 1,5-Di(2-Fluorophenyl)-3-Mercaptoformazan, A New Metal Extractant, Anal. Chim. Acta, 1977, 88, 177.

[27] S. Liu, J. Zubieta, Chemical and X-ray Structural Characterization of Diphenylcarbazone and Diphenylthiocarbazone Complexes of Molybdenum(VI), $\left(n-\mathrm{Bu}_{4} \mathrm{~N}\right)\left[\mathrm{MoO}_{2}\left(\mathrm{C}_{6} \mathrm{H}_{5} \mathrm{NNC}(\mathrm{X}) \mathrm{NNC}_{6} \mathrm{H}_{5}\right)\left(\mathrm{C}_{6} \mathrm{H}_{5} \mathrm{NNC}(\mathrm{X}) \mathrm{NN}(\mathrm{H}) \mathrm{C}_{6} \mathrm{H}_{5}\right)\right](\mathrm{X}=\mathrm{O}$ or S) and $\left.\left(n \mathrm{Bu}_{4} \mathrm{~N}\right) \mathrm{MoOCl}_{3}\left(\mathrm{C}_{6} \mathrm{H}_{5} \mathrm{NNC}(\mathrm{O}) \mathrm{NNC}_{6} \mathrm{H}_{5}\right)\right]$; Isolation of 2,3-Diphenyltetrazolium-5-thiolate, $\mathrm{C}_{6} \mathrm{H}_{5} \mathrm{NNC}(\mathrm{S}) \mathrm{NNC}_{6} \mathrm{H}_{5}$, from the Reaction of Diphenylthiocarbazone with Molybdate, Polyhedron, 1989, 8, 677-688. 
[28] Y. Singh, S. B. Tyagi, R. N. Kapoor, Synthesis of Some New Organozirconium(IV) Dithizonates, Acta Chim. Hungarica, 1989, 126, 665-672.

[29] S. B. Tyagi, B. Singh, R. N. Kapoor, Reactions of Hafnium(IV) Isopropoxide Isopropanolate with 1,5-Diarylthiocarbazones, Acta Chim. Hungarica, 1986, 122, 229-234.

[30] Y. Singh, R. Sharan, R. N. Kapoor, Synthesis and Spectra Characteristics of Bis(indenyl)titanium(IV) Dithizonate Complexes, Synth. React. Inorg. Met.-Org. Chem., 1987, 17, 759-771. 
Table 1

Conditions for preparation of nitro- and amino- polystyrenes

Nitration of Polystyrenes

\begin{tabular}{|c|c|c|c|c|c|c|c|c|c|c|c|}
\hline $\begin{array}{l}\text { Sample } \\
\text { number }\end{array}$ & $\begin{array}{l}\text { Polysty- } \\
\text { rene }(\mathrm{g})\end{array}$ & $\begin{array}{l}\mathrm{mL} \text { of } \\
\mathrm{HNO}_{3}\end{array}$ & $\begin{array}{c}\mathrm{mL} \text { acetic } \\
\text { anhydride }\end{array}$ & $\begin{array}{l}\mathrm{mL} \text { acetic } \\
\text { acid }\end{array}$ & $\begin{array}{l}\text { Time } \\
\text { (hr) }\end{array}$ & $\begin{array}{l}\text { Sample } \\
\text { number }\end{array}$ & $\begin{array}{l}\mathrm{g} \text { of } \\
\text { sample }\end{array}$ & $\begin{array}{l}\mathrm{g} \text { of } \\
\mathrm{SnCl}_{2}\end{array}$ & $\begin{array}{l}\mathrm{mL} \text { of } \\
\mathrm{aq} . \mathrm{HCl}\end{array}$ & Temp. ${ }^{\circ} \mathrm{C}$ & $\begin{array}{l}\text { Time } \\
\text { (hr) }\end{array}$ \\
\hline $\begin{array}{l}2-112 \\
3-2 \\
3-24\end{array}$ & $\begin{array}{l}60 \\
59 \\
30\end{array}$ & $\begin{array}{l}15 \\
20 \\
15\end{array}$ & $\begin{array}{c}150 \\
150 \\
50 \\
\mathrm{H}_{2} \mathrm{SO}_{4}\end{array}$ & $\begin{array}{l}50 \\
45\end{array}$ & $\begin{array}{l}2 \\
4 \\
4\end{array}$ & $\begin{array}{l}2-113 \\
3-7 \\
3-25\end{array}$ & $\begin{array}{l}57 \\
57 \\
28\end{array}$ & $\begin{array}{l}125 \\
125 \\
125\end{array}$ & $\begin{array}{l}250 \\
250 \\
250\end{array}$ & $\begin{array}{l}\text { room } \\
\text { room } \\
\text { room }\end{array}$ & $\begin{array}{l}24 \\
48 \\
72\end{array}$ \\
\hline $\begin{array}{l}1.16 \mathrm{~A} \\
2-60 \\
2-88\end{array}$ & $\begin{array}{l}10 \\
32 \\
50\end{array}$ & $\begin{array}{l}3.2 \\
50 \\
15\end{array}$ & $\begin{array}{l}41 \\
120 \\
200\end{array}$ & $\begin{array}{c}9 \\
30 \\
45\end{array}$ & $\begin{array}{c}5 \\
2.5 \\
1\end{array}$ & $\begin{array}{l}1-16 B \\
2-61 \\
2-94\end{array}$ & $\begin{array}{c}5 \\
34 \\
45\end{array}$ & $\begin{array}{c}5 \\
125 \\
125\end{array}$ & $\begin{array}{c}5 \\
250 \\
250\end{array}$ & $\begin{array}{l}\text { room } \\
\text { reflux } \\
\text { reflux }\end{array}$ & $\begin{array}{l}48 \\
30 \\
28\end{array}$ \\
\hline $3-20$ & 30 & 15 & $\begin{array}{c}50 \\
\mathrm{H}_{2} \mathrm{SO}_{4}\end{array}$ & & 3 & $3-21$ & 28 & 125 & 250 & room & 72 \\
\hline $\begin{array}{l}2-87 \\
3-22\end{array}$ & $\begin{array}{l}50 \\
30\end{array}$ & $\begin{array}{l}30 \\
15\end{array}$ & $\begin{array}{c}200 \\
50 \\
\mathrm{H}_{2} \mathrm{SO}_{4}\end{array}$ & 45 & $\begin{array}{l}3 \\
4\end{array}$ & $\begin{array}{l}2.97 \\
3.23\end{array}$ & $\begin{array}{l}58 \\
28\end{array}$ & $\begin{array}{l}150 \\
125\end{array}$ & $\begin{array}{l}250 \\
250\end{array}$ & $\begin{array}{l}\text { reflux } \\
\text { room }\end{array}$ & $\begin{array}{l}48 \\
72\end{array}$ \\
\hline $\begin{array}{l}2-89 \\
3-18\end{array}$ & $\begin{array}{l}50 \\
30\end{array}$ & $\begin{array}{l}15 \\
15\end{array}$ & $\begin{array}{c}200 \\
50 \\
\mathrm{H}_{2} \mathrm{SO}_{4}\end{array}$ & 45 & $\begin{array}{c}0.5 \\
3\end{array}$ & $\begin{array}{l}2.93 \\
3-19\end{array}$ & $\begin{array}{l}58 \\
28\end{array}$ & $\begin{array}{l}125 \\
125\end{array}$ & $\begin{array}{l}250 \\
250\end{array}$ & $\begin{array}{l}\text { reflux } \\
\text { room }\end{array}$ & $\begin{array}{l}48 \\
72\end{array}$ \\
\hline
\end{tabular}

Reduction of Nitropolystyrenes 


\section{Figure Captions}

Figure 1: Conversion of polystyrene to aminopoiystyrene followed by diazotization.

Figure 2: (a) Conversion of a primary aromatic amine to the corresponding nitroformaldehyde arylhydrazone; (b) Conversion of a primary aromatic amine to the corresponding diarylthiocarbazone.

Figure 3: The procedure of Chwastowska and Kosiarska ${ }^{10}$ for coupling diazotized aminopolystyrene with diphenylthiocarbazone (dithizone). This procedure leads to a supported diarylthiocarbazone with the indicated "extra" azo chromophore. An analogous procedure is used in this work to couple diazotized aminopolystyrene with di- $\beta$-naphthylthiocarbazone.

Figure 4: The procedure used in this work to anchor a diarylthiocarbazone chromophore onto a polystyrene matrix. 

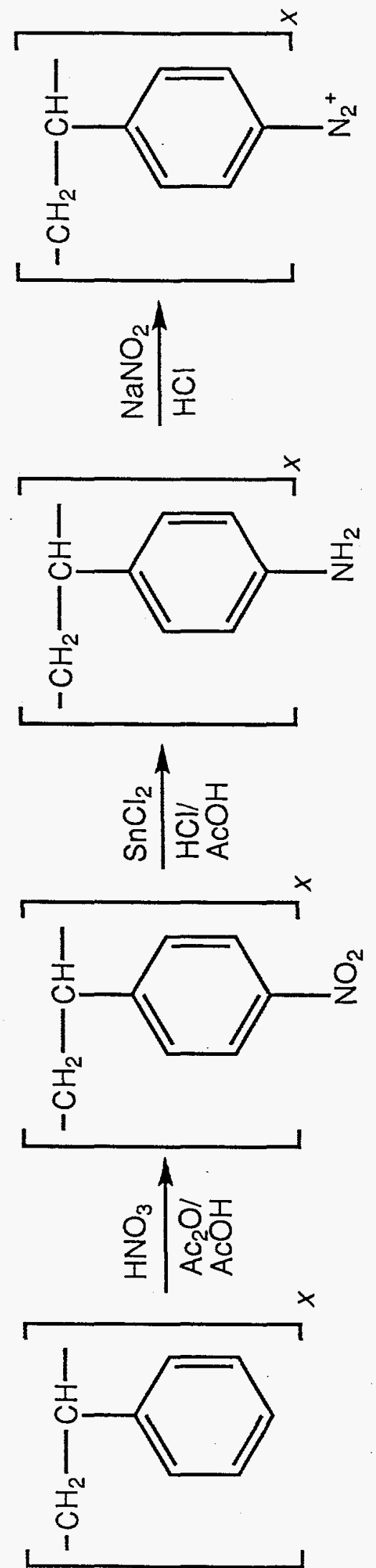


$$
\mathrm{RNH}_{2} \stackrel{\mathrm{HNO}_{2}}{\longrightarrow} \mathrm{RN}_{2}+\frac{\mathrm{CH}_{3}^{\mathrm{NaOH}}}{\mathrm{H}_{2} \mathrm{O} / \mathrm{EtOH}} \underbrace{\mathrm{RNH}-\mathrm{N}=\mathrm{NO}_{2}}_{\begin{array}{l}
\text { Nitroformaldehyde } \\
\text { Arylhydrazone }
\end{array}}
$$

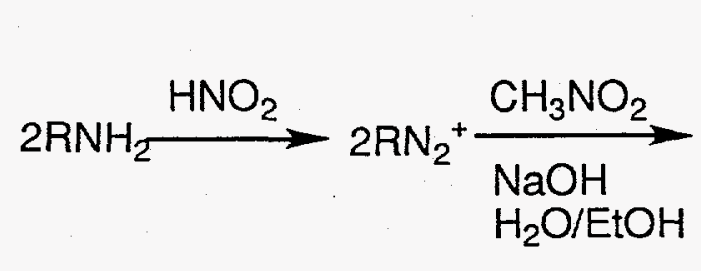<smiles>N=NCC(N=N)[N+](=O)[O-]</smiles>

Diarylnitroformazan

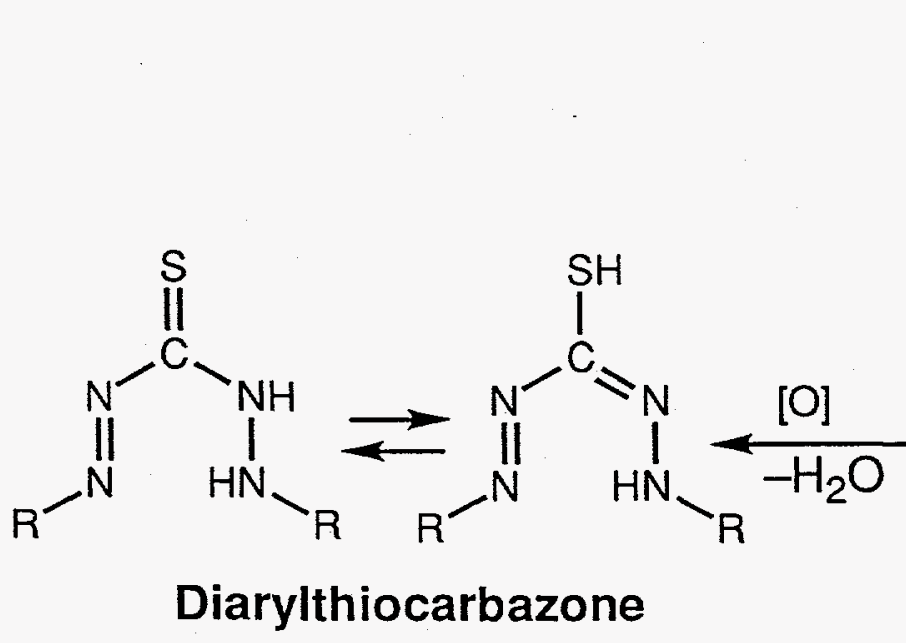<smiles>NN=C(NN)S[Hg]O[Na]</smiles>
Diarylthiocarbazide 

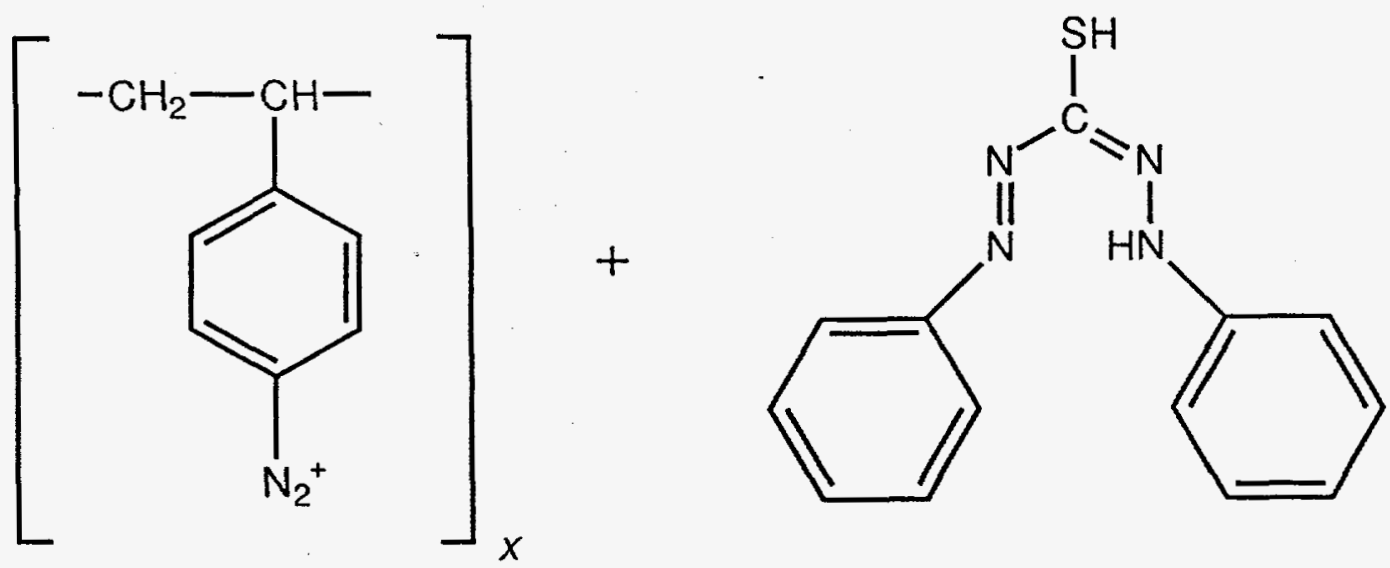

Polystyrenediazonium ion + Diphenylthiocarbazone
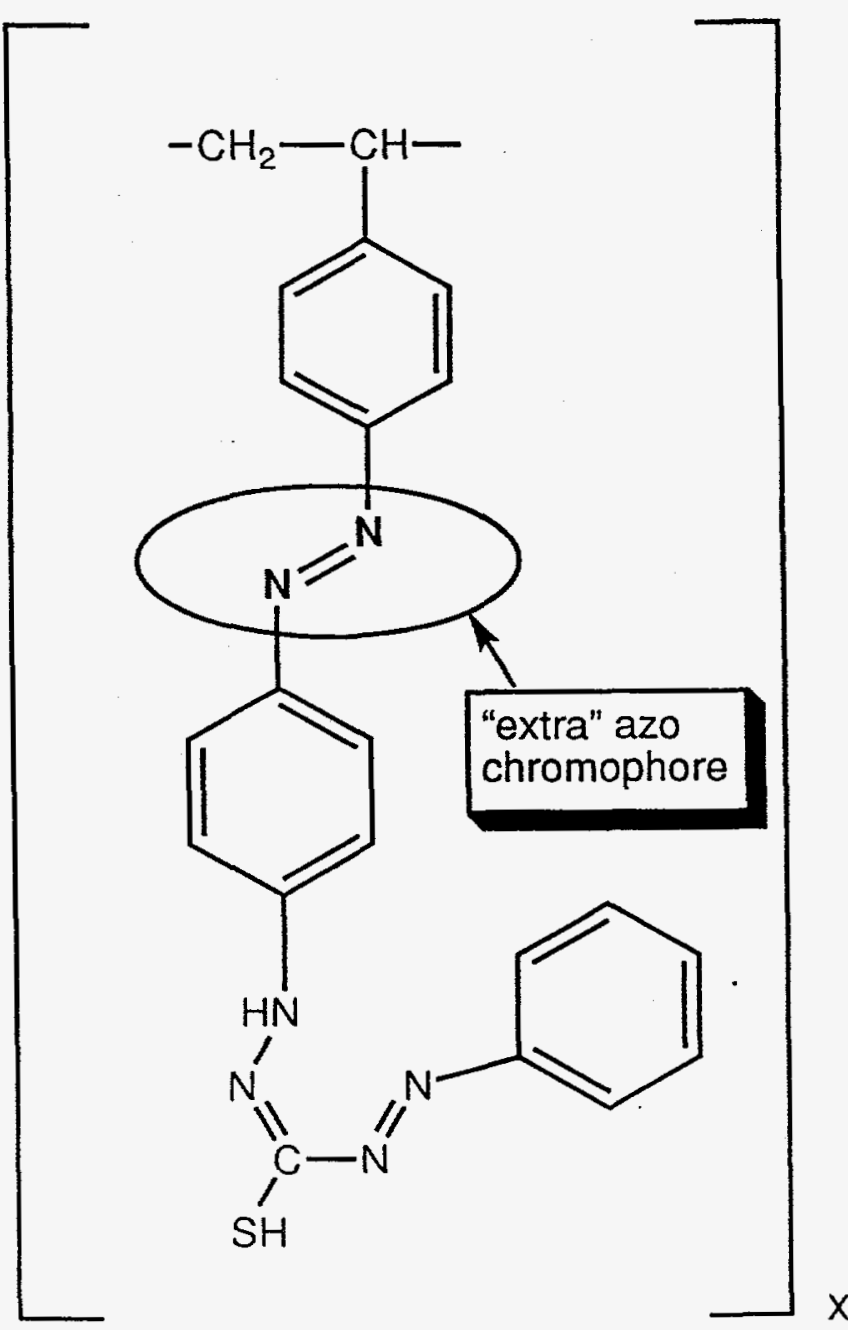


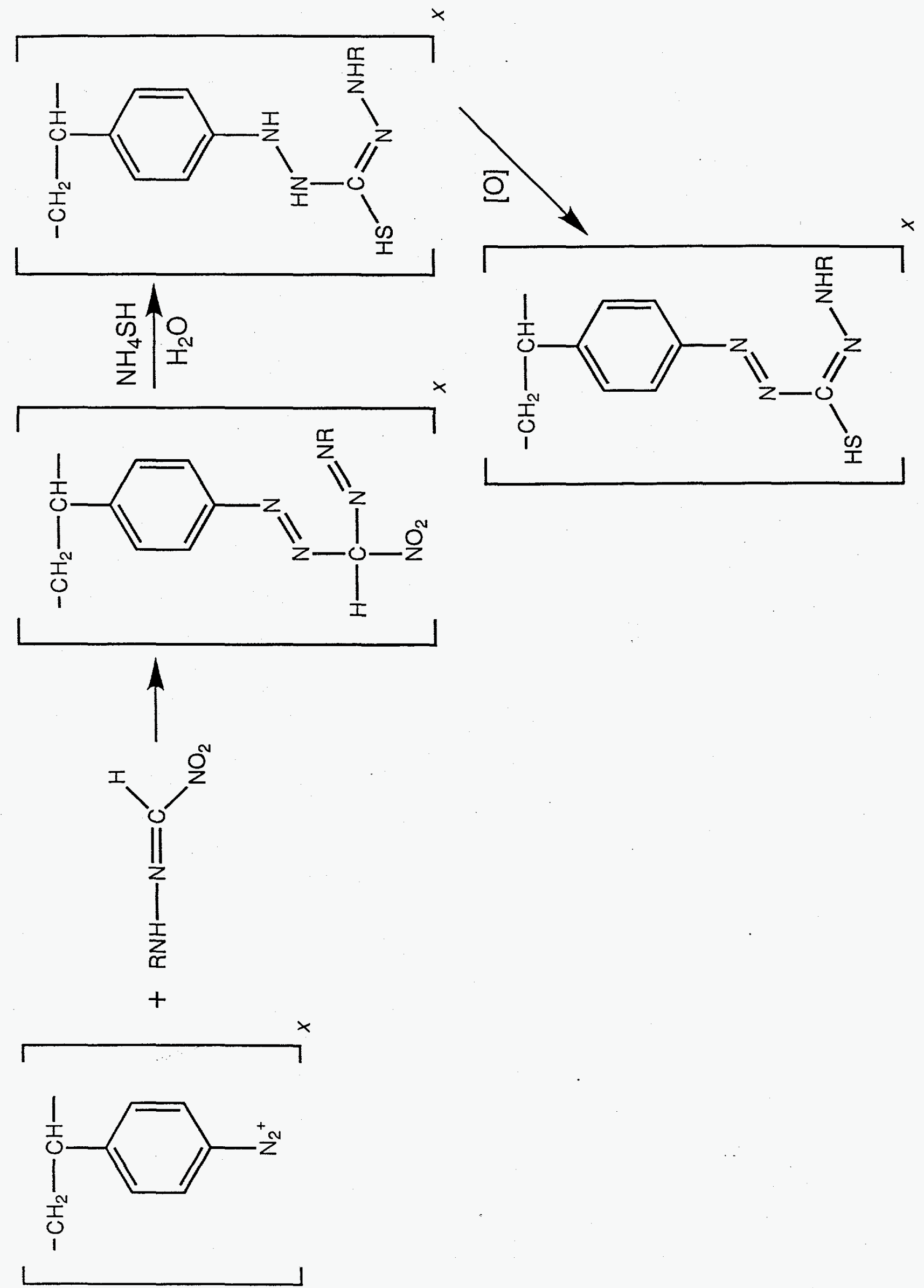

